\title{
PERFILES DE LOS USUARIOS DEL BUFETE JURÍDICO GRATUITO DE LA UNIVERSIDAD DE SONORA (2014-2015) PARA SU MEJORA LEGAL, ACADEMICA, SOCIAL Y ECONOMICA
}

\author{
Miguel Angel Hernández Sánchez ${ }^{1}$
}

SUMARIO: Resumen; I. Introducción; II. Metodología; III. Marco Teórico; IV. Condiciones Sociales y Laborales de los Usuarios del Bufete Jurídico; a). Género; b). Edad; c). Estado Civil; d). Hijos; e). Ingresos; f). Escolaridad; g). Estabilidad Laboral; h). Seguridad Social. I). Tipos de Asunto; j). Ocupación; V. Perfil del Usuario; a). Aspectos Personales; b).- Aspectos Personales; c) Fuente de Información para investigación y Aprendizaje sociales; VI. Conclusiones.

\section{RESUMEN}

En el documento se describe la evolución y características del Bufete Juridico de la UNISON, así como algunos interesantes hallazgos (2014-2015)que dan la pauta para ser atendidos y mejorar los servicios gratuitos jurídicos que se presta a una mayoría de la sociedad de escasos recursos económicos y en general de todos los niveles socioeconómicos, derecho fundamental reconocido a nivel internacional, que brinda la oportunidad, de preparar y capacitar a sus alumnos en la práctica, así como potencial fuente de información valiosa para la comprensión, análisis e investigación por investigadores de otras disciplinas.

PALABRAS CLAVE: Bufete Jurídico Gratuito, perfil de usuarios, potencial fuente de información

\footnotetext{
1 Docente Investigador de Tiempo Completo del Departamento de Derecho de la DCS, URC de la Universidad de Sonora, correo electrónico:

miguel.hernandez@unison.mx
} 
Perfiles de los usuarios del Bufete Jurídico gratuito de la Universidad de

Sonora (2014-2015) para su mejora legal, académica, social y económica Año 11, Número 21 julio-diciembre de 2019 Miguel Ángel Hernández Sánchez

\title{
USERS PROFILE'S OF THE FREE LAW FIRM OF THE UNIVERSITY OF SONORA (2014-2015) FOR THEIR LEGAL, ACADEMIC, SOCIAL AND ECONOMIC IMPROVEMENT
}

\begin{abstract}
The document describes the evolution and characteristics of the Law Firm of UNISON, as well as some interesting findings (2014-2015) that set the standard for being attended to and improving the free legal services provided to a majority of society with few economic resources and in general of all the socioeconomic levels, fundamental right recognized at international level, that offers the opportunity, to prepare and to train its students in the practice, as well as source of valuable information for the understanding, analysis and investigation by researchers of Other disciplines.
\end{abstract}

KEY WORDS: Free Law Firm, user profile, potential source of information

\section{INTRODUCCIÓN}

Con la presente colaboración, nos sumamos al merecido homenaje a Don Emilio Margáin Manautou reconocido jurisconsulto quien dedicó gran parte de su obra a las nuevas generaciones de estudiosos y cultivadores del Derecho administrativo y del Derecho Fiscal, al conminarles en cada oportunidad de estar frente a ellos, a continuar estudiando con más ímpetu...para recuperar en beneficio de los contribuyentes y/o autoridades hacendarias, grandes áreas del derecho fiscal y administrativo en manos, hoy por hoy, de otros profesionales de las ciencias econoómicas administrativas, y con ello contribuir al combate a la corrupción en la que se incurre, en el mayor de los casos por ignorancia mas que por premeditada inobservancia del orden jurídico impositivo local, federal y/o internacional y principlmente, no olvidando al término de su Carrera que lo que son y serán se lo deben al país que les permitió salir adelante. Que son privilegiados frente al grueso de su generación que no tuvo acceso ya no a la educación superior sino ni siquiera 
a la educación media ${ }^{2}$... Dado que nuestra presente colaboración, coincide, con la procupación del reconocido jurisconsulto Margáin Manautou, de formar mejores estudiantes ---futuros abogados--- los interesantes hallazgos [obtenidos del aálisis de los expedientes del Bufete Juridico de la UNISON (2014-2015) que dan la pauta para ser atendidos y mejorar los servicios gratuitos jurídicos que se presta, a una mayoría de la sociedad de escasos recursos económicos] se suman al legado invaluable de la extensa y docta obra del insigne Maestro Don Emilio Margáin Manautou.

Durante el Verano del 2015, presenté un proyecto de servicio social ante las instancias correspondientes - mismo que resultó aprobado- que tenía como objetivo conocer el perfil de los usuarios del Bufete Jurídico Gratuito del Departamento de Derecho y poder establecer o actualizar la reglamentación con la actualmente cuenta la institución para prestar los servicios Jurídico. Para lograrlo se hizo una revisión de los estudios socioeconómicos que levantan las trabajadoras sociales, a toda persona que requiere de dichos servicios. $Y$ el propósito era conocer el principal género que requería de los servicios jurídicos, cuál era la edad, el estado Civil, el número de Hijos, los ingresos que percibían, el grado de escolaridad, si tenían alguna ocupación, si contaban con estabilidad laboral y si tenían seguridad social, igualmente conocer cuál es el tipo de asunto que más solicitaban. Todo ese cúmulo de información que recolectamos nos permite establecer el perfil del usuario de los servicios gratuitos del Bufete Jurídico de la Universidad de Sonora para establecer o actualizar la reglamentación de dicha institución prestadora de servicios a la sociedad y mejorar Legal, Académica, Social y Económicamente a ese Organismo. Pero además surgida de este tratamiento de la información, nos percatamos que existe un vasto repertorio de información de situaciones sociales que tienen los usuarios que pueden ser aprovechadas por otras profesiones a nivel de investigación pertenecientes a las ciencias sociales. Que debidamente estructurada pueden resultar investigaciones importantes de nuestra realidad social.

\footnotetext{
${ }^{2}$ Margaín Manautou Emilio,Política Fiscal 2016 en BIOLEX Revista Jurídica del Departamento de Derecho, Número
} 
Perfiles de los usuarios del Bufete Jurídico gratuito de la Universidad de

Sonora (2014-2015) para su mejora legal, académica, social y económica

Año 11, Número 21 julio-diciembre de 2019 Miguel Ángel Hernández Sánchez

\section{METODOLOGÍA}

Trabajo Exploratorio donde se revisó Información personal y laboral que extrajimos de 2128 estudios socioeconómicos que realizaron las trabajadoras sociales a los usuarios al solicitar el servicio y el tipo de servicio jurídico prestado en el período de 2014 a marzo del 2015, por lo tanto la investigación es cuantitativa en cuanto todos los datos extraídos y cualitativo en cuanto a la interpretación que se les dio a los mismos.

\section{MARCO TEÓRICO}

La Declaración Universal de los Derechos Humanos consagra en su Artículo 3 que toda Persona tiene Derecho a la vida la Libertad y a la Seguridad de su persona (Organizacion de las Naciones Unidas,, 2016) además dicha declaración en su Artículo 12 señala "Nadie será objeto de injerencias arbitrarias en su vida privada, su familia, su domicilio o su correspondencia, ni de ataques a su honra o a su reputación. Toda persona tiene derecho a la protección de la ley contra tales injerencias $o$ ataques.

De la misma manera la Declaración Americana de Derechos Humanos establece lo siguiente en su Artículo 18 - Derecho de justicia Toda persona puede ocurrir a los tribunales para hacer valer sus derechos. Asimismo debe disponer de un procedimiento sencillo y breve por el cual la justicia lo ampare contra actos de la autoridad que violen, en perjuicio suyo, alguno de los derechos fundamentales consagrados constitucionalmente (Aprobada en la Novena Conferencia Internacional Americana, 1948)

De igual forma, en la Convención Americana de Derechos Humanos Pacto de San José de Costa Rica señala en su Artículo 8. Garantías Judiciales:

1. Toda persona tiene derecho a ser oída con las debidas garantías y dentro de un plazo razonable, por un juez o tribunal competente independiente e imparcial establecido con anterioridad por la ley, en la sustanciación de cualquier acusación penal formulada contra ella, o para la determinación de 
sus derechos y obligaciones de orden civil, laboral, fiscal o de cualquier otro carácter. (Convencion Americana de Derechos Humanos, 1981)

Así mismo para la elaboración del presente trabajo consultamos los perfiles que establece la Secretaria de Economía que los clasifica en seis; - baja-baja, baja alta; media baja, media alta, y; alta baja, alta alta- que establece el Programa Nacional de Protección a los Derechos del Consumidor 2013-2018 que existen en México (Secretaria de Economía, 2014); sin embardo para el presente investigación se tomaron solamente tres compactando los niveles bajo, medio y alto. Ello debido a que los datos extraídos de los estudios socioeconómicos levantados así lo recomiendan.

Dicha estratificación la define dicho programa de la siguiente manera:

Baja: - baja baja: está constituida por trabajadores temporales e inmigrantes, comerciantes informales, desempleados, y gente que vive de la asistencia social que representa el 35\% de la población general. - Baja Alta: está conformada principalmente por obreros y campesinos (agricultores). Es la fuerza física de la sociedad, ya que realiza arduos trabajos a cambio de un ingreso ligeramente superior al sueldo mínimo que representa el $25 \%$ de la población en el país.

En este primer perfil, la Secretaría de Desarrollo Social en sus lineamientos y Criterios Generales para la Definición y medición de la Pobreza publicado en el Diario Oficial de la Federación con Fecha 16 de Junio del 2010 dentro de las disposiciones Generales; Titulo Segundo de la Definición de la Pobreza, establecen a quienes se considera se encuentran en pobreza;

CUARTO. La condición de la pobreza considera las condiciones de vida de la población a partir de tres espacios: el del bienestar económico; el de los derechos sociales y el del contexto territorial

QUINTO. El espacio de bienestar económico comprenderá las necesidades asociadas a los bienes y servicios que pueda adquirir la población mediante el Ingreso. 
Perfiles de los usuarios del Bufete Jurídico gratuito de la Universidad de

Sonora (2014-2015) para su mejora legal, académica, social y económica

Año 11, Número 21 julio-diciembre de 2019 Miguel Ángel Hernández Sánchez

SEXTO. El espacio de los derechos sociales se integrará a partir de las carencias de la población en el ejercicio de sus derechos para el desarrollo social....

SEPTIMO. El espacio del contexto territorial incorporará aspectos que trascienden al ámbito individual (que pueden referirse a características geográficas, sociales y culturales, entre otras); en específico, aquellos asociados al grado de cohesión social, así como otros considerados relevantes para el desarrollo social. (Secretaría de Desarrollo Social, 2010)

La misma CONEVAL (Consejo Nacional de Evaluación de la Política de Desarrollo Social, 2014) establece cuáles son los indicadores pobreza que son: rezago Educativo; Servicios de Salud; seguridad Social, en situación de pobreza; vulnerables por carencias sociales y de ingresos.

Media: Media Baja: Formada por oficinistas, técnicos, supervisores y artesanos calificados. Sus ingresos no son muy sustanciosos pero son estables, se estima que sea el $20 \%$ de la población nacional. Media Alta: Incluye a la mayoría de hombres de negocios y profesionales que han triunfado y que por lo general constan de buenos y estables ingresos económicos. Se estima que sea aproximadamente $14 \%$ de la población nacional.

En cuanto a este nivel medio se establece que: "El concepto de clase media es elástico porque incluye a personas con ingresos muy distintos. El término comprende profesionales, comerciantes, burócratas, empleados, académicos, todos los cuales tienen un ingreso suficiente para vivir" (De la Calle Luis y Rubio Luis, 2010)

Alta: Alta Baja: la integran familias que son ricas de pocas generaciones atrás. Sus ingresos económicos son cuantiosos y muy estables. Se estima que sea aproximadamente el $5 \%$ de la población nacional. Alta Alta: La componen antiguas familias ricas que durante varias generaciones han sido prominentes y cuya fortuna es tan añeja que se ha olvidado cuándo y cómo la obtuvieron. Se estima que sea aproximadamente 1\% de la población nacional. (Secretaria de Economía, 2014) 
De la misma manera se incluye como marco teórico, el reglamento del Bufete Jurídico vigente que fue elaborado en 26 de Octubre del 1972. Documento que no obstante estar vigente no se encuentra contemplado dentro de la normatividad que establece la página oficial de la Universidad de Sonora.

El cual en sus DISPOSICIONES GENERALES establece;

Artículo 3. El establecimiento del bufete Jurídico persigue el cumplimiento de los siguientes objetivos:

Fracción I Prestar servicios a personas de escasos recursos económicos, sin recibir remuneración alguna por concepto de Honorarios.

\section{CONDICIONES SOCIALES Y LABORALES DE LOS USUARIOS DEL BUFETE JURIDICO.}

\section{a. GÉNERO:}

Del total de los solicitantes del servicio jurídico en ese periodo de tiempo el $56 \%$ fueron mujeres y $44 \%$ fueron hombres lo que representa que hay una proporción del $6 \%$ entre los solicitantes de dicho servicio. Ello representa que durante el periodo de tiempo que se analizó 1185 fueron mujeres y 943 fueron hombres

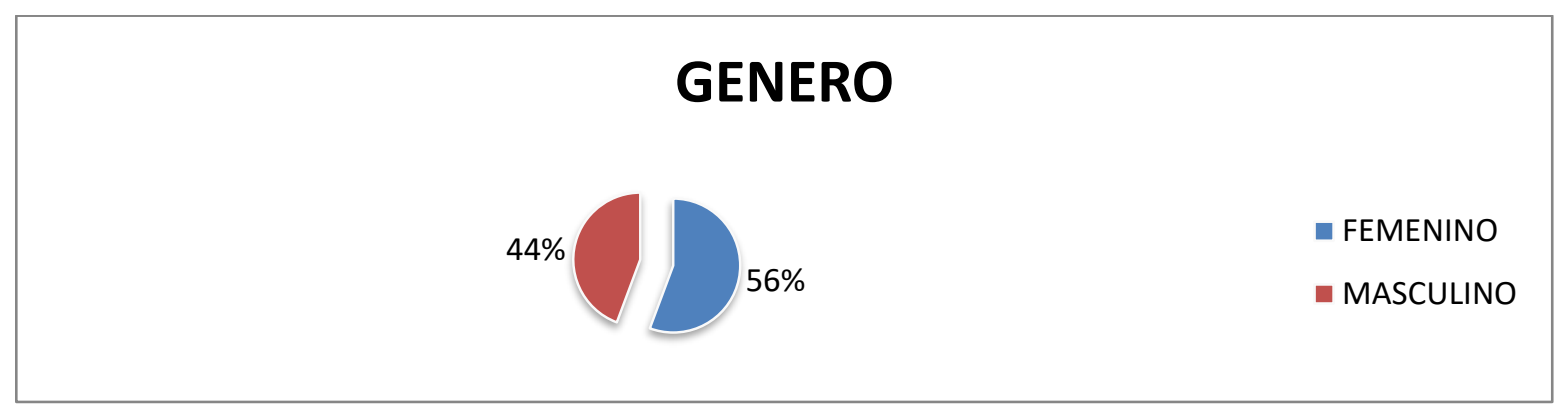

Tabla propia.

b. EDAD.

En la revisión de documentos se encontró que las personas que solicitan el servicio; un 30\% son personas de 41 a 50 años de edad; un 29\% de 30 a 40 años; 
Perfiles de los usuarios del Bufete Jurídico gratuito de la Universidad de Sonora (2014-2015) para su mejora legal, académica, social y económica Año 11, Número 21 julio-diciembre de 2019 Miguel Ángel Hernández Sánchez un $17 \%$ de personas entre 24 y 29 años; un $7 \%$ de sujetos entre 18 a 23 años y de 51 a 60 años; y el resto varían entre 61 a 100 años de edad: Por lo que para los efectos de número se tiene que; 642 personas eran de entre 41 a 50 años; 611 de entre 30 a 40 años; 359 entre 24 a 29 años; 145 de entre 18 a 23 años; 142 de entre 51 a 60 años; 78 de entre 61 a 70 años; 118 que no quisieron o no supieron su edad y el resto de 71 a 100 años.

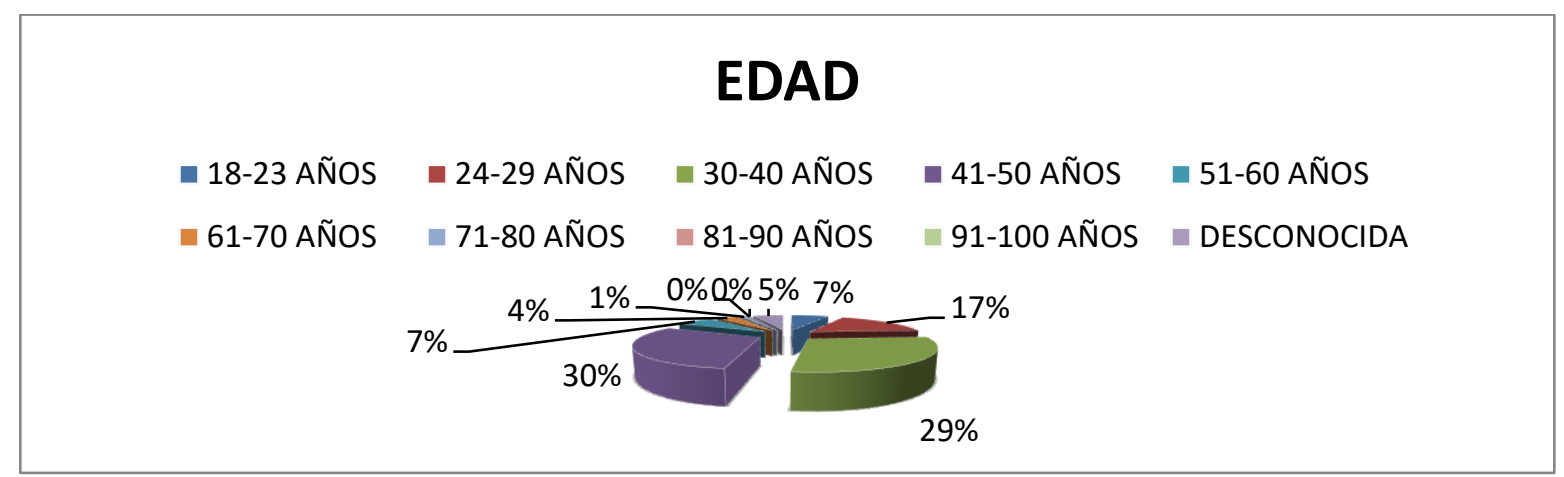

Tabla propia.

\section{c. ESTADO CIVIL}

En cuanto al estado civil se encontró que los usuarios del bufete jurídico; 1121 personas que representa el $57 \%$ son casados; 677 que representa el $32 \%$ son Solteros; 100 que representa el 5\% viven en Unión Libre; 66 que representa el 3\% son Viudos; y 56 que representa otro 3\% son Divorciados; el resto que no aparece en porcentaje viven en concubinato y se desconoce.

\section{ESTADO CIVIL}

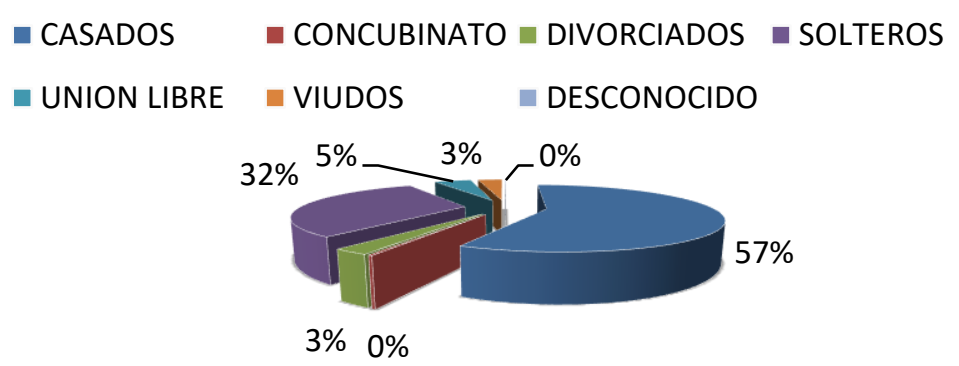


Tabla propia.

d. HIJOS:

En relación con los hijos los usuarios que asistieron al bufete jurídico se indica que 1481 personas que representa el 70\% manifestaron tener entre 1-3 hijos; 437 que representa el $20 \%$ manifestaron no tener hijos; 193 personas que representan el $9 \%$ indicaron que tienen de 4 a 6 hijos, y; por ultimo 17 personas que representa el $1 \%$ señalaron tener entre 7 y 11 hijos.

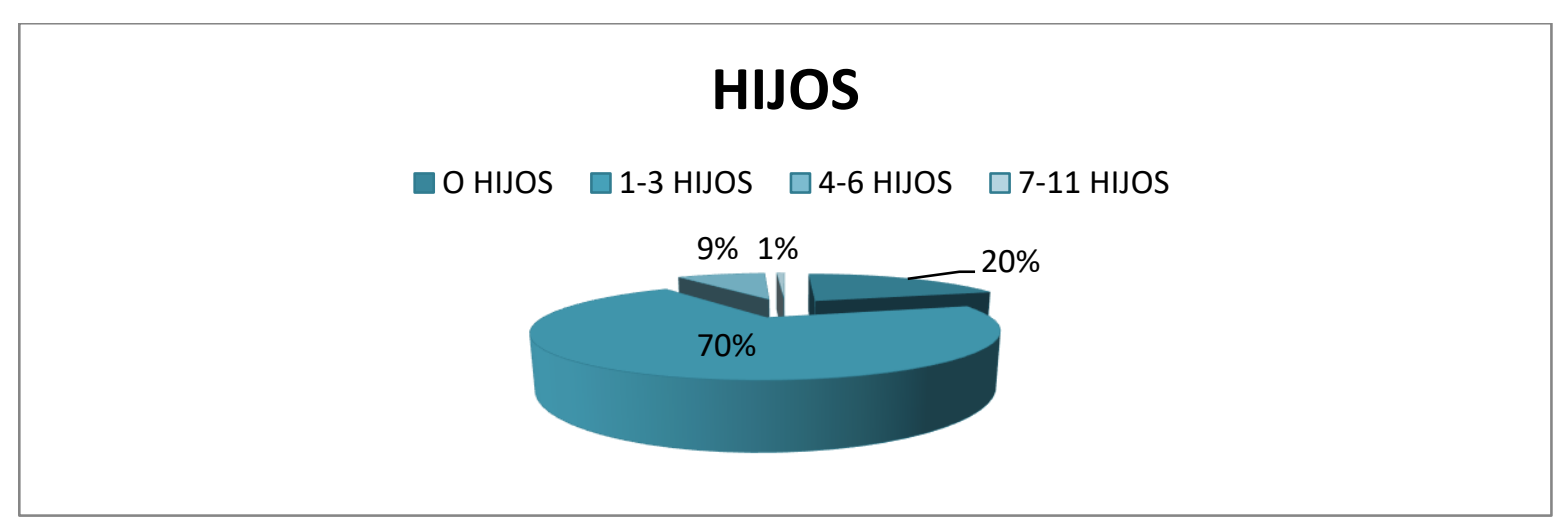

\section{e. INGRESOS}

En cuanto a la revisión de los estudios socioeconómicos se establece que los ingresos que perciben los usuarios mensualmente son; 923 personas que representa el $43 \%$ manifestaron que perciben de 0 a 5000 pesos; 879 personas que representa el $41 \%$ indicaron que no tenían ingreso alguno; 267 que representa el $13 \%$ manifestaron que recibían entre 5001 y 10000 pesos; 22 personas que representa el $2 \%$ revelaron que tenían un ingreso entre 10001 y 15000 pesos ; y, por ultimo 37 personas que representa el 1\% establecieron que tenían ingresos de entre 15001 a 25000 pesos. 
Perfiles de los usuarios del Bufete Jurídico gratuito de la Universidad de Sonora (2014-2015) para su mejora legal, académica, social y económica Año 11, Número 21 julio-diciembre de 2019 Miguel Ángel Hernández Sánchez

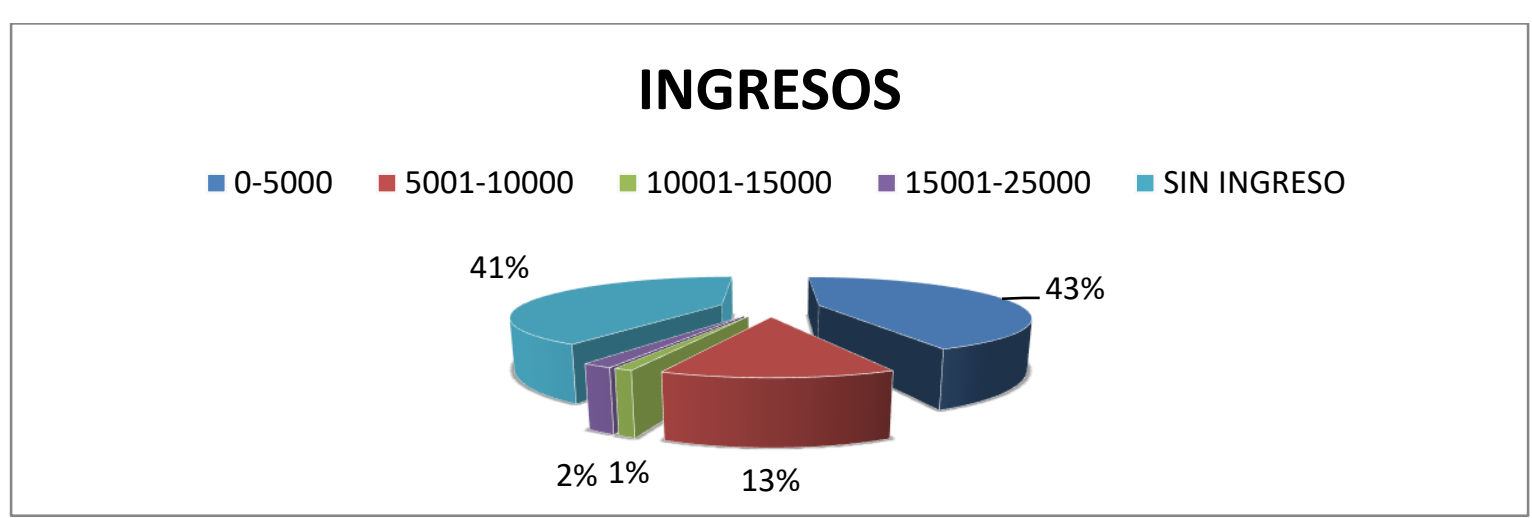

\section{f. ESCOLARIDAD:}

Por lo que respecta el nivel educativo de los usuarios del bufete son los siguientes: 747 que representa el 35\% manifestaron que tenían nivel de Preparatoria; 719 que constituye el $34 \%$ tiene un nivel de escolaridad de Secundaria; 375 que representa el 18\% tienen un nivel de licenciatura terminada o trunca; 243 que representa el 11\% dijeron tener nivel de Primaria, y; finalmente 43 personas que representa el $2 \%$ subrayaron que eran analfabetas:

\section{ESCOLARIDAD}

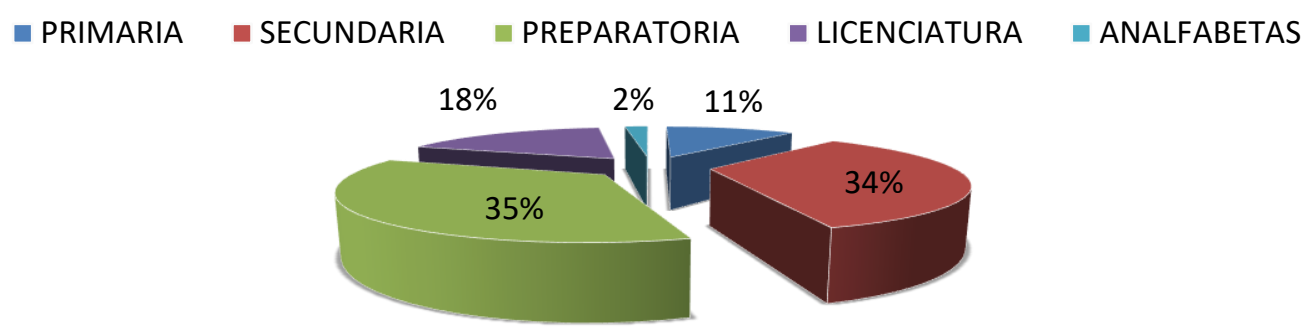

\section{g. ESTABILIDAD LABORAL:}

En cuanto a la estabilidad laboral manifestaron los usuarios; 1209 que representa el 57\% indicaron no tener ninguna estabilidad laboral; 527 que 
representa el 25\% manifestaron tener trabajos fijos; y 392 de los usuarios que representa el $18 \%$ indicaron que tenían trabajos eventuales:

\section{ESTABILIDAD LABORAL}

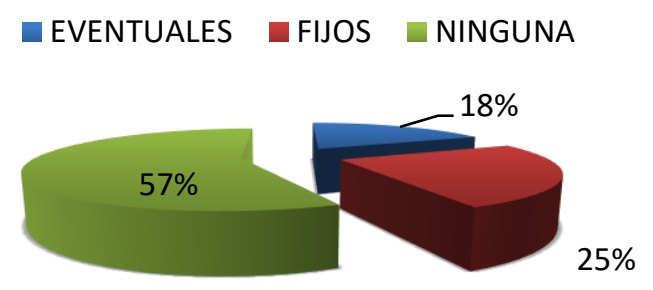

\section{h. SEGURIDAD SOCIAL:}

Dentro de la información recabada las instituciones de salud que les brindan servicio a estos usuarios fueron; 895 personas que representa el $42 \%$ no tienen ningún tipo de seguridad social; 628 que representa el 30\% tiene como seguridad social al Instituto Mexicano del Seguro Social; 426 usuarios que representa el 20\% tiene Seguro Popular; 67 Personas que representa el 3\% tiene ISSSTESON; 30 usuarios que representa el $1 \%$ tiene ISSSTE y 83 personas que representa $4 \%$ no indicaron que tipo de seguridad social tienen:

\section{SEGURIDAD SOCIAL}

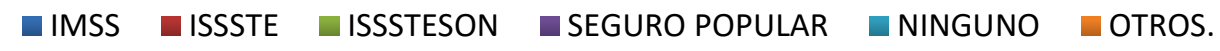

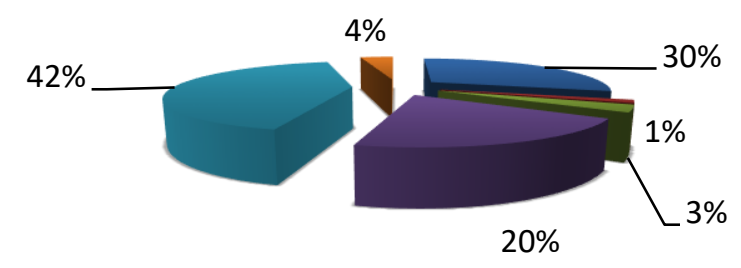

i. TIPO DE ASUNTO:

Los servicios jurídico prestados y más solicitado por los usuarios fueron: 730 personas que representa el $34 \%$ solicita servicios de tipo Civil; 600 personas que 
Perfiles de los usuarios del Bufete Jurídico gratuito de la Universidad de Sonora (2014-2015) para su mejora legal, académica, social y económica Año 11, Número 21 julio-diciembre de 2019 Miguel Ángel Hernández Sánchez representa el 28\% solicita servicios de tipo Familiar; 199 usuarios que representa el 10\% solicita solamente asesorías ( de todo tipo); 198 usuarios que representa el $9 \%$ solicita servicios de tipo laboral; 150 de las personas que representa el $7 \%$ solicita trámite para asuntos de tipo Mercantil; 135 de los solicitantes que representa el 6\% solicita asunto de tipo Penal, y ; 116 que representa el 6\% asuntos de amparo.

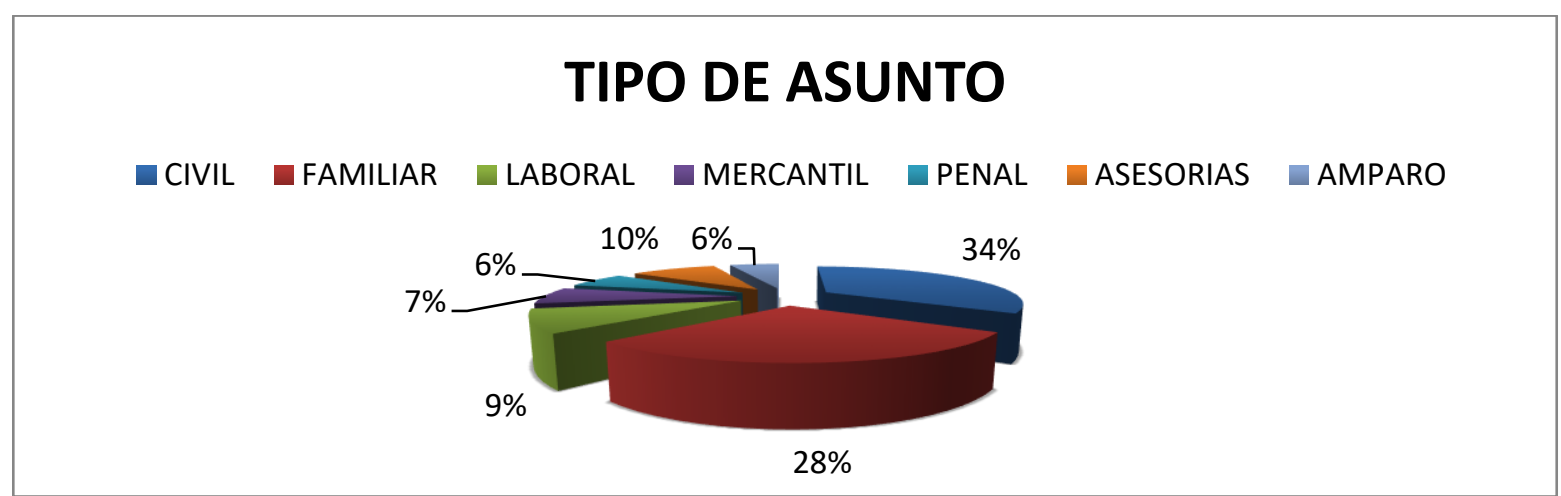

\section{j. OCUPACIÓN:}

Así mismo, la presente investigación permitió conocer cuál es la ocupación de los usuarios y se encontró que 2024 personas que representa el 95\% indicaron que sí, tenían algún tipo de ocupación; y solamente 104 que representa el 5\% manifestaron no tener ninguna ocupación

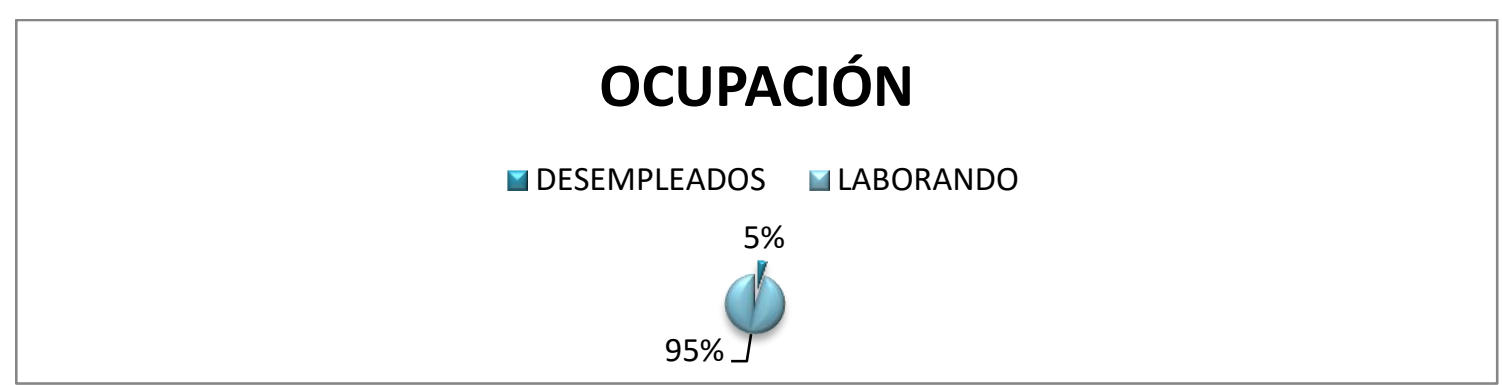

Tabla Propia

Basado en lo anterior se deduce el siguiente: 


\section{PERFIL DE LOS USUARIOS}

El porcentaje entre Hombres y Mujeres que solicitan el servicio del Bufete Jurídico Gratuito básicamente es igual, lo que representa que la institución esta bien posicionada para prestar el servicio jurídico a ambos Géneros. Así mismo, se estableció que la edad más productiva de la vida entre los 30 a 50 años es cuando más requieren los servicios del bufete; de la misma manera, la gran mayoría su estado civil es de casados o están solteros; que, independientemente de su estado civil tienen entre 0 a 3 hijos y que solamente el 10\% tienen entre 4 y 11 hijos. Un rubro que si llama la atención son los ingresos que perciben los usuarios ya que $84 \%$ tienen ingresos que fluctúan de 0 ingresos, hasta 5000 pesos mensuales; no pasando desapercibido que también entre ellos hay un 16\% que tienen ingresos que van desde los 5001 a 25000 pesos; un dato oportuno de reconocer como novedoso es, que un $18 \%$ tiene estudios de licenciatura terminada o trunca; que un $69 \%$ tienen o bien secundaria o preparatoria y que solamente un $11 \%$ tiene primaria. En ese contexto y con el propósito de concentrar la información que se obtuvo, se dividió en dos aspectos; personales y laborales de los usuarios para su análisis y mejor comprensión. 
Perfiles de los usuarios del Bufete Jurídico gratuito de la Universidad de Sonora (2014-2015) para su mejora legal, académica, social y económica Año 11, Número 21 julio-diciembre de 2019 Miguel Ángel Hernández Sánchez

a. ASPECTOS PERSONALES:

\begin{tabular}{|c|c|c|c|c|c|c|c|c|c|}
\hline \multicolumn{2}{|c|}{ Genero } & \multicolumn{2}{|l|}{ Edad } & \multicolumn{2}{|l|}{ Estado Civil } & \multicolumn{2}{|l|}{ Hijos } & \multicolumn{2}{|l|}{ Escolaridad } \\
\hline \multirow{2}{*}{$\begin{array}{l}\text { Mujer } \\
56 \%\end{array}$} & \multirow{6}{*}{$\begin{array}{l}\text { Hombre } \\
44 \%\end{array}$} & \multirow[t]{6}{*}{18 a 23 años } & \multirow[t]{6}{*}{$7 \%$} & \multirow[t]{4}{*}{ Casados } & \multirow[t]{4}{*}{$57 \%$} & \multirow{2}{*}{$\begin{array}{l}0 \\
\text { hijos }\end{array}$} & \multirow[t]{2}{*}{$20 \%$} & \multirow{3}{*}{$\begin{array}{l}\text { Primaria } \\
\text { Secundaria }\end{array}$} & $11 \%$ \\
\hline & & & & & & & & & \multirow[t]{2}{*}{$34 \%$} \\
\hline & & & & & & \multirow{2}{*}{$\begin{array}{l}1-3 \\
\text { hijos }\end{array}$} & \multirow[t]{2}{*}{$70 \%$} & & \\
\hline & & & & & & & & \multirow[t]{2}{*}{ preparatoria } & \multirow[t]{2}{*}{$35 \%$} \\
\hline & & & & \multirow[t]{2}{*}{ Concubinato } & \multirow[t]{2}{*}{$0 \%$} & \multirow{2}{*}{$\begin{array}{l}4-6 \\
\text { hijos }\end{array}$} & \multirow[t]{2}{*}{$9 \%$} & & \\
\hline & & & & & & & & \multirow[t]{2}{*}{ Licenciatura } & \multirow[t]{2}{*}{$18 \%$} \\
\hline & & \multirow[t]{3}{*}{24 a 29 años } & \multirow[t]{3}{*}{$17 \%$} & \multirow[t]{2}{*}{ Divorciados } & \multirow[t]{2}{*}{$3 \%$} & \multirow{2}{*}{$\begin{array}{l}7-11 \\
\text { hijos }\end{array}$} & \multirow[t]{2}{*}{$1 \%$} & & \\
\hline & & & & & & & & \multirow[t]{2}{*}{ Analfabeta } & \multirow[t]{2}{*}{$2 \%$} \\
\hline & & & & Soltero & $32 \%$ & & & & \\
\hline & & \multirow[t]{2}{*}{30 a 40 años } & $29 \%$ & Viudos & $3 \%$ & & & & \\
\hline & & & & desconocido & $0 \%$ & & & & \\
\hline & & 41 a 50 años & $30 \%$ & Unión libre & $5 \%$ & & & & \\
\hline & & 51 a 60 años & $7 \%$ & & & & & & \\
\hline & & 61 a 70 años & $4 \%$ & & & & & & \\
\hline & & 71 a 80 años & $1 \%$ & & & & & & \\
\hline & & 81 a 90 años & $0 \%$ & & & & & & \\
\hline & & 91 a 100 años & 100 & & & & & & \\
\hline & & $\begin{array}{l}\text { Edad } \\
\text { desconocida }\end{array}$ & $5 \%$ & & & & & & \\
\hline & & & & & & & & & \\
\hline
\end{tabular}

Elaboración propia

En cuanto al aspecto laboral se encontró también cuatro situaciones sumamente importantes y que tienen que ver con la ocupación, la estabilidad laboral, la seguridad social y los ingresos, que impacta necesariamente en los aspectos de salud y económicos. En éstos rubros encontramos que, el $95 \%$ de los usuarios tienen una ocupación laboral y $5 \%$ son desempleados; en cuanto a la estabilidad laboral se tiene; que 57\% no tiene estabilidad laboral; $25 \%$ estabilidad fija y $18 \%$ estabilidad eventual - señalando que los primero son aquellos que brincan de trabajo en trabajo y los eventuales son contratados para desarrollar un trabajo específico por un tiempo u obra determinada- en cuanto a la seguridad social el $42 \%$ de los que no tienen estabilidad laboral no tienen seguridad Social: 
del $25 \%$ que tienen estabilidad Laboral; $30 \%$ tienen Seguro Social y del $18 \%$ de estabilidad eventual 30\% tiene Seguro Popular; 4\% no tiene Seguridad Institucional; $4 \%$ tiene Isssteson y $1 \%$ Issste. Y por lo que respecta a los ingresos el $41 \%$ no tiene ningún Ingreso; 43\% tiene ingresos de 0 a 5000 pesos; 13\% de 5001 a 10000 Pesos: $2 \%$ de 10001 a 15000 Pesos y $1 \%$ de 15001 a 25000 pesos.

b. Aspectos Laborales:

\begin{tabular}{|c|c|c|c|}
\hline Ocupación & Estabilidad laboral & Seguridad social. & Ingresos \\
\hline \multirow[t]{6}{*}{ 95\% ocupado } & $\begin{array}{ll}57 \% \quad \text { No } & \text { tiene } \\
\text { estabilidad } & \end{array}$ & $\begin{array}{l}42 \% \text { Sin Seguridad } \\
\text { Social }\end{array}$ & $41 \%$ sin Ingresos \\
\hline & 25\% Estabilidad fija & $30 \%$ Seguro Social & $\begin{array}{l}43 \% \text { de } 0 \text { a } 5000 \\
\text { pesos }\end{array}$ \\
\hline & \multirow[t]{4}{*}{$\begin{array}{l}18 \% \quad \text { Estabilidad } \\
\text { eventual }\end{array}$} & $30 \%$ Seguro Popular & $\begin{array}{l}13 \% \text { de } 5001 \text { a } \\
10000\end{array}$ \\
\hline & & $\begin{array}{l}4 \% \quad \text { Sin seguridad } \\
\text { Institucional }\end{array}$ & $\begin{array}{llll}2 \% & \text { de } & 10001 & a \\
15000 & & \end{array}$ \\
\hline & & $3 \%$ Isssteson & $\begin{array}{llll}1 \% & \text { de } & 15001 & \text { a } \\
25000 & & \end{array}$ \\
\hline & & $1 \%$ Issste & \\
\hline 5\% Desempleados & & & \\
\hline
\end{tabular}

Elaboración propia

\section{c. FUENTE DE INFORMACIÓN PARA INVESTIGACIÓN Y APRENDIZAJES SOCIALES}

Ahora bien, el presente trabajo que tenía como propósito hacer un estudio de campo de los perfiles del usuario del Bufete Jurídico, puede visualizarse no solamente como una fuente de información e investigación para el propio bufete, sino que además puede ser una fuente para estudios más profundos de tipo, sociológico, de trabajo social, Psicológicos, de comunicación etc. Proporcionado a Investigadores de otras área sociales una fuente inagotable para abordar diversos estudios destinados a conocer otros aspectos sociales del usuario que solicita el servicio y que, como se demuestra en el presente trabajo los usuarios, no solamente es de escasos recursos sino de todos los niveles sociales así como de diferentes 
Perfiles de los usuarios del Bufete Jurídico gratuito de la Universidad de

Sonora (2014-2015) para su mejora legal, académica, social y económica

Año 11, Número 21 julio-diciembre de 2019 Miguel Ángel Hernández Sánchez

problemáticas laborales, conductuales y sociales en general. Pero además de esa oportunidad también puede beneficiar a los jóvenes estudiantes de diversas carreras pertenecientes a la División de Ciencias sociales para que puedan acercarse a prestar sus prácticas profesionales o servicio social. Ahora bien, ya que no hay costo para los usuarios que se atienden en dicho bufete podría establecerse en forma obligatoria que la única forma de acceder a dicho servicio es colaborando en investigaciones que algún investigador quiera realizar y/o alumnos quieren poner en práctica sus conocimientos.

\section{CONCLUSIONES:}

Es recomendable para efectos de la prestación del servicio jurídico que a partir del Reglamento que se actualice o de nueva creción, se debe establecer, que los servicios jurídico se prestarán a los usuarios considerados del nivel más bajo de recursos económicos; a los de nivel medio se le puede prestar el servicio asesoría y excepcionalmente patrocinarlo en algún asunto jurídico y a los de nivel alto alto únicamente se les podrá otorgar asesoría siempre y cuando aporten una cuota de recuperación para el sostenimiento de la Institución, otorgandoles excepcionalmente patrocinio. Por ello se establecen las siguientes conclusiones:

Primero.- Como la función del Bufete Jurídico es prestar Asesoría Jurídica a personas de escasos recursos económicos, se tomaron en consideración las definiciones de los niveles bajo, medio y alto que hacen tanto la Procuraduría Federal del Consumidor así como las definiciones de pobreza que realiza la Secretaría de Desarrollo Social, estableciendo en esa estratificación, los datos personales y laborales recabados a los usuarios del bufete, quedando establecidos de la siguiente manera:

Nivel Bajo: las características consideradas para ubicar en este nivel fueron: a). el $100 \%$ de los usuarios que solicitan el servicio; b). Que su ocupación fuera sin ninguna estabilidad o bien, estuvieran desempleados; c). que su educación fuera la 
mínima, primaria, secundaria o sin ninguna instrucción; d). que devengara de 0 a 5000 pesos o que no tuviera ingresos y; e). que no tuvieran seguridad social o fuera prestada por el IMSS y el Seguro Popular.

\begin{tabular}{|l|l|l|l|l|}
\hline Genero H/M & Ocupación & Educación & Ingresos & $\begin{array}{l}\text { Seguridad } \\
\text { Social: }\end{array}$ \\
\hline $100 \%$ & $\begin{array}{l}\text { Sin Estabilidad: 52\% } \\
\text { Desempleados 5\% }\end{array}$ & $\begin{array}{l}\text { Primaria; 11\% } \\
\text { Secundaria; 34\% } \\
\text { Analfabeta: } 2 \%\end{array}$ & $\begin{array}{l}\text { 0 a 5000: 41\% } \\
\text { Sin ingresos: 43\% }\end{array}$ & $\begin{array}{l}\text { Sin seguridad } \\
\text { social: } 42 \% \\
\text { Imss: 3\% } \\
\text { S.Popular: } 20 \%\end{array}$ \\
\hline Total $100 \%$ & Total: $57 \%$ & Total 47\% & Total 84\% & $63 \%$ \\
\hline
\end{tabular}

Elaboración propia

Nivel Medio: para éste nivel se consideraron las siguiente variables: a). el $100 \%$ de los usuarios que solicitaron el servicio; b). hombres y mujeres que tuvieran una ocupación de eventuales; c). que tuvieran como educación la preparatoria o carrera técnica; d). que devengaran un promedio entre 5001 y 10000 pesos y; e). que estuvieran asegurados por el ISSSTESON E ISSSTE;

\begin{tabular}{|l|l|l|l|l|}
\hline Género & Ocupación & Educación & Ingresos & $\begin{array}{l}\text { Seguridad } \\
\text { Social }\end{array}$ \\
\hline $100 \%$ & Eventuales; $18 \%$ & $\begin{array}{l}\text { Preparatoria } 0 \\
\text { carrera técnica } \\
35 \%\end{array}$ & $5001-10000:$ & $\begin{array}{l}\text { Isssteson: } 3 \% \\
\text { Issste: } 1 \%\end{array}$ \\
\hline Total: $100 \%$ & Total: $18 \%$ & Total: $35 \%$ & Total: $13 \%$ & Total: $4 \%$ \\
\hline
\end{tabular}

Elaboración propia

Nivel Alto: Para el nivel más alto se establecieron las siguiente variables: a) $100 \%$ de los solicitantes del Servicio Jurídico; b. aquellos que solicitaron el servicio que tuvieron una ocupación fija; c). una educación a nivel licenciatura terminada 0 trunca, d). que recibieran una atención de medicina particular, y; e). que devengaran un salario entre 10001 a 25000 pesos mensualmente. 
Perfiles de los usuarios del Bufete Jurídico gratuito de la Universidad de Sonora (2014-2015) para su mejora legal, académica, social y económica Año 11, Número 21 julio-diciembre de 2019 Miguel Ángel Hernández Sánchez

\begin{tabular}{|l|l|l|l|l|}
\hline Género: & Ocupación & Educación & Ingresos & $\begin{array}{l}\text { Seguridad } \\
\text { Social }\end{array}$ \\
\hline $100 \%$ & Fijos 25\% & $\begin{array}{l}\text { Licenciatura } \\
\text { completa/ } \\
\text { incompleta: 18\% }\end{array}$ & $\begin{array}{l}\text { 20001 a } \\
\text { 25000: 3\% }\end{array}$ & $\begin{array}{l}\text { Particular: } \\
4 \%\end{array}$ \\
\hline Total 100\% & Total 25\% & Total 18\% & Total 3\% & Total 4\% \\
\hline
\end{tabular}

Elaboración propia

Tabla de Totales:

\begin{tabular}{|l|l|l|l|l|}
\hline Genero & Ocupación & Educación: & Ingresos & $\begin{array}{l}\text { Seguridad } \\
\text { Social: }\end{array}$ \\
\hline Bajo: $100 \%$ & Bajo: $57 \%$ & Bajo: 47\% & Bajo: 84\% & Bajo: 92\% \\
\hline $\begin{array}{l}\text { Intermedio: } \\
100 \%\end{array}$ & Intermedio: & Intermedio: 35\% & $\begin{array}{l}\text { Intermedio: } \\
13 \%\end{array}$ & Intermedio: 4\% \\
\hline Alto: $100 \%$ & Altos: $25 \%$ & Alto: $18 \%$ & Alto: 3\% & Alto: 4\% \\
\hline
\end{tabular}

Elaboración propia

Segundo. De lo anterior se deducen cuatro situaciones - social, económico, académico y legal- con las que debe estar comprometida la Universidad de Sonora ante la sociedad Sonorense:

A nivel social: Beneficiar con dicho servicio a los hombres y mujeres que se acercan más al nivel bajo en los aspectos económico - ingresos- , sociales Seguridad Social- educativos - Educación obligatoria -así con menor estabilidad laboral - ocupación- . A los de nivel medio es claro que si se les puede proporcionar el servicio de asesoría, pero por lo que respecta a patrocinar asuntos se debe ser cuidadoso y excepcionalmente patrocinarlos; pero, definitivamente a los que se están considerando con un ingreso de nivel alto, a éstos se les debe solicitar una cuota de recuperación para darles asesoría, y excepcionalmente patrocinarlos,puesto que estos tienen la capacidad económica para pagar sus servicios jurídicos. 
A Nivel Económico: Aplicar con estricto respeto y aprovechamiento los recursos económicos que son canalizados por la Universidad de Sonora al Departamento de Derecho para el sostenimiento del Bufete Jurídico Gratuito y que éstos se utilicen con más precisión social, para atender a las personas con escasos recursos económicos. De tomarse en consideración la anterior propuesta, el impacto inmediato seria la reducción de gastos, que se puedan aprovechar, en mejorar las instalaciones físicas y de equipos de oficina y de cómputo.

A nivel Académico: Mejoraría sin duda la capacitación práctica de los estudiantes del Departamento de Derecho que prestan sus servicios realizando sus Prácticas Profesionales y/o de Servicio Social, puesto que la disminución en asuntos que tradicionalmente se tramitan (civil,penal,familiar) será menor, lo que representa que los asesores jurídicos del Bufete Jurídico tendrán el tiempo necesario para capacitarse, investigar y aplicar metodologías de la enseñanza práctica y personalizar la atención, en asuntos jurídicos de diversas ramas del Derecho (fiscal,administrativo,internacional,aduanero,ambiental, entre otras) que ofrecen areas de oportunidad laboral a los futuros abogados pero que requieren de especialización. De la misma manera puede beneficiar a todos los profesores Investigadores de las Diversas licenciaturas de la División de Ciencias Socialesaún de otras profesiones de la Universidad de Sonora- a realizar investigaciones directamente relacionadas con su profesión - actividad no explorada- teniendo al alcance información social aprovechable en cualquier investigación, o bien, para que alumnos de diversas profesión a la de derecho tenga un lugar donde puedan realizar sus prácticas profesionales o de servicio social.

A nivel legal. Es importante establecer por último, que el anterior reporte permitirá también a las autoridades que toman decisiones sobre la normatividad de la Universidad de Sonora, tomando como base los anteriores datos revisar, actualizar o dictar una normatividad acorde con los tiempos actuales que vive la prestación de servicios jurídicos esta Institución. Mientras eso acontece todos los asuntos jurídicos deberán ser debidamente recibidos y tratados excepto los asuntos de carácter mercantil o hipotecario; de la misma manera se admitirán sólo los de 
Perfiles de los usuarios del Bufete Jurídico gratuito de la Universidad de Sonora (2014-2015) para su mejora legal, académica, social y económica Año 11, Número 21 julio-diciembre de 2019 Miguel Ángel Hernández Sánchez

carácter individual no colectivo, pudiendo haber algún tipo de excepción cuando involucre algún tipo de asunto que así lo amerite.

\section{Bibliografía}

Consejo Nacional de Evaluación de la Política de Desarrollo Social. CONEVAL México 2014 , Obtenido de http://www.coneval.org.mx/coordinacion/entidades/Sonora/Paginas/pobreza-2014.aspx

De la Calle Luis y Rubio Luis. Clasemediero; Pobre no más, desarrollado aún no, México 2010, Centro de Investigación para el Desarrollo A.C. .

Diario Oficial de la Federacion 7 Mayo de 1981.Convencion Americana de Derechos Humanos, México, 1981. Obtenido de https://www.scjn.gob.mx/libro/instrumentosconvencion/pag0259.pdf consultada 14 de Agosto del 2016

Diario Oficial de la Federacion . Secretaría de Desarrollo Social,México, 2010. Obtenido de http://www.dof.gob.mx/ 16 de Junio del 2010

Diario Oficial de la Federacion, Secretaria de Economía, 2014,. Obtenido de Primera Sección pp. 4: http://dof.gob.mx/nota_detalle.php?codigo=5343849\&fecha=08/05/2014 7 de Mayo 2014

López Puleio María Fernanda. Centro de Estudios de Justicia de las Americas, 2016, Obtenido de buscar; Asistencia Legal y Defensa Pública: Documento de Fundamentación

Aprobada en la Novena Conferencia Internacional Americana. (1948). Obtenido de Declaracion Americana de los Deberes y Derechos del Hombre:

https://www.oas.org/dil/esp/Declaraci\%C3\%B3n_Americana_de_los_Derechos_y_Debere s_del_Hombre_1948.pdf consultada 13 de Agosto del 2016

Organizacion de las Naciones UnidasDeclaración Universal de los Derechos Humanos,(2016). Obtenido de http://www.un.org/es/documents/udhr/ consultado 12 Agosto del 2016

Recibido 3 de junio de 2018 Aceptado 7 de Noviembre de 2019 